\title{
Optimal Voltage and Current Selection for Turboelectric Aircraft Propulsion Networks
}

\author{
Kingsley Ibrahim, Student Member, IEEE, Suresh Sampath, and Devaiah Nalianda
}

\begin{abstract}
Deploying electrical systems for aircraft propulsion have been identified as a potential solution, for reducing the environmental impact of the increasing air transport usage. However, the implementation of this system needs to be done at a suitable voltage and current combination. The aim of this work is to propose a clear procedure, for deriving a suitable voltage and current for an electrical propulsion system, based on the aircraft dimensions and thrust requirement. The approach presented, considers feasibility and minimum mass as boundary and target respectively. The results show that the fan configuration and thrust requirement directly influence the choice of optimal voltage and current. This is due to the varied impact on device sizes and overall propulsion system performance. Major drivers of the selected voltage and current are the loading coefficient, speed and torque requirement of the fan. The knowledge of these is a requirement to arrive at an optimal voltage for the propulsion system.
\end{abstract}

Index Terms - Sizing, Speed, Torque, Motor, Design.

\section{INTRODUCTION}

$\mathrm{T}$ HE need to reduce the contribution of aviation activities to greenhouse emissions has become imperative, owing to increasing demand in the sector. Significant efforts have been put in, to develop a framework for this reduction, together with other environmental impacts like noise. The NASA N+3 goals [1], [2] set in 2008 and the European Flightpath 2050[3] set in 2011, are examples. These frameworks highlight a holistic approach to solving these problems, by viewing aviation activities as a single integrated system. A broad division into aircrafts, airports, logistics and passengers is made[4], and these require individual and synergistic optimization.

On the aircrafts side, several concepts have been proposed, to improve the performance, in terms of efficiency (fuel burn per mission) and noise pollution[2], [5]. These rely on the hypothesis, that optimum thermal and propulsive efficiencies can be achieved, if the power generation and propulsion components of turbofans are decoupled[6].

Two major approach for decoupling the fan and turbine are either mechanical or electrical transmission. The mechanical approach would require a gear box between the turbine spool and the fan shaft. The electrical approach on the other hand, involves the deployment of electromechanical power conversion devices (generators and motors), along with cables, to transmit the power from the turbine to the fan shaft. Such an arrangement offers not only the benefits of running individual propulsors at optimized speed as with gear boxes, but also frees

The authors are with the Propulsion Engineering Centre, School of Aerospace, Transport and Manufacturing (SATM) Cranfield University, Cranfield, Bedfordshire MK43 0AL, United Kingdom. (e-mail: up the design space, by offering the flexibility in positioning them around the aircraft. This helps achieve noise reduction and more efficient thrust production, through higher bypass ratios.

Despite these promises, several challenges need to be overcome in order to achieve such a propulsion system. These are related to size, large power management and servicing. Therefore, the design aim is to achieve electric propulsion of aircraft at the safest, most economic and power dense cost.

A few aircrafts have been proposed [7], [8], [9], [10], [11], [12] which can broadly be categorized into the more electric aircraft (MEA) and all electric aircraft (AEA). These respectively propose to partly or totally replace the mechanical propulsion system with electrical systems. Several possible configurations abound, with overlapping attributes of the two major approaches. Fig. 1 shows a classification of electrical powertrains proposed in [11].

To obtain a certain amount of thrust, the delivery of sufficient speed and torque to the fan shaft, requires that the motor be operated at a corresponding voltage and current combination. The selection of such voltage and current is an important part of the electrical propulsion systems design. This is to ensure not only that the devices are optimally sized, but also that they function normally, while delivering the required amount of power. A gap is found in literature, for a clear procedure to determine what voltage level is optimal for a given configuration and aircraft.

This work presents a method for the selection of the optimal voltage and current, specific for a given electrical aircraft propulsion system. Only a turboelectric configuration using conventional (non-superconducting) devices and no batteries is considered. Component level details are presented, to reflect the influence of voltage and current magnitudes on the overall devices that constitute the propulsion system. Focus is given first to the overall mass, since it is shown in [13], that the electrical propulsion systems' specification, has significantly less impact on efficiency than it has on mass.

\section{BACKGROUND}

Reference [14] presented a method for the calculation of safe voltage rating for an aircraft wiring system. This was only for the insulated cables and did not consider the impact of the selected voltage, on the sizing and performance of the other devices in the system. Similar studies aimed at the selection of the optimal voltage, at the optimal propulsion system size were

Kingsley.a.ibrahim@cranfield.ac.uk; devaiah.nalianda@cranfield.ac.uk). s.sampath@ cranfield.ac.uk; 

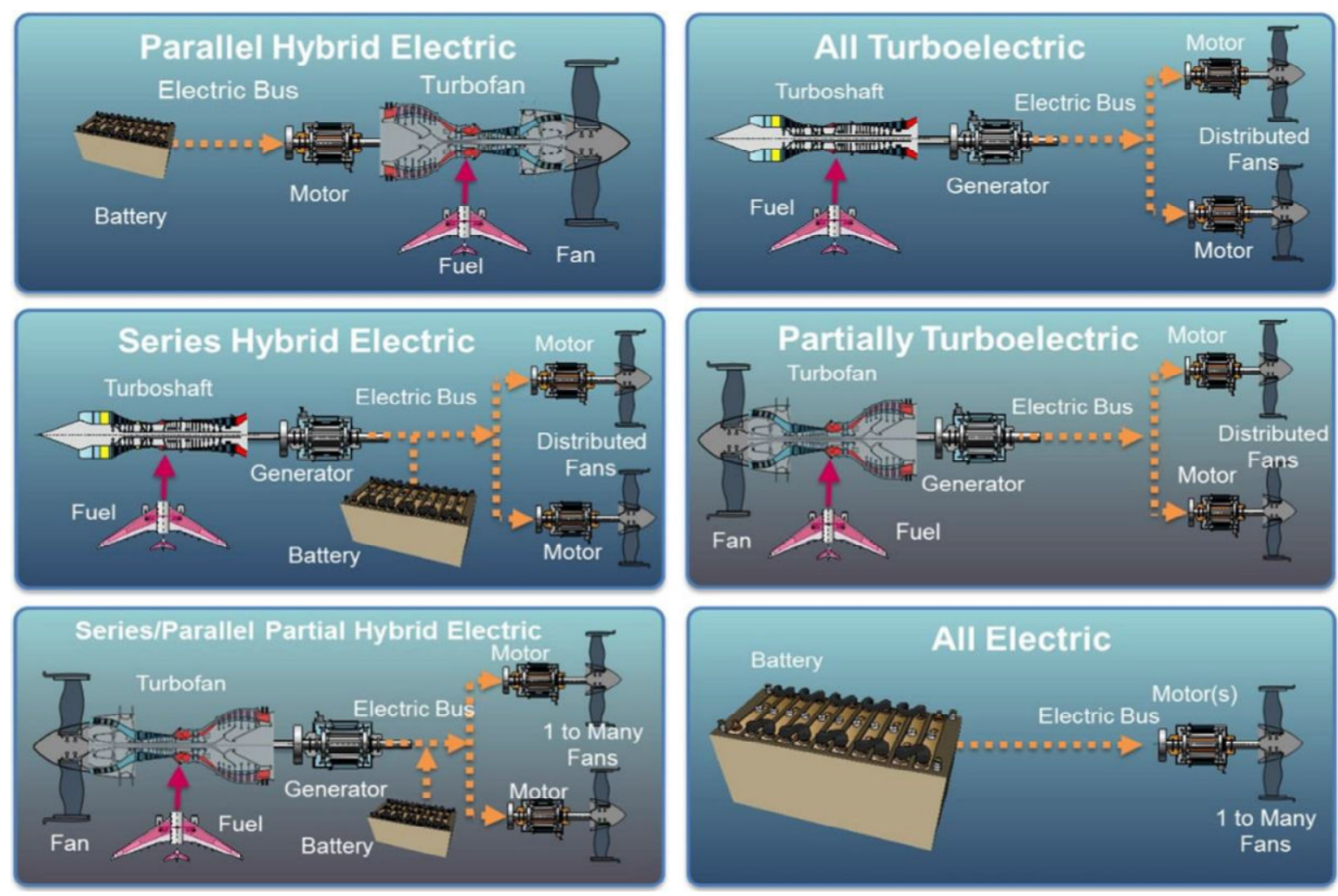

Fig. 1. Classification of electrical propulsion trains[11].

performed in [15] and [16]. The two studies covered parameter selection and design procedure, based on superconducting technologies. However, non-overlapping voltage range was proposed for the same aircraft from both studies. A study of electrical components, sizing of electrical machines and investigation of superconducting turboelectric aircrafts was performed in [17]. The voltage selection was done for only the electrical machines. Reference [18] presented an approach for modelling superconducting motors using a modified conventional machine dynamic model. An assumed voltage of $28 \mathrm{~V}$ was used, detailed propeller to motor matching is performed but other electrical components were not considered. The power flow technique was used in [19] to correctly predict buses voltages and currents at different torque-speed combination. This was obtained for steady state and transient state scenario involving a sudden change (increase) in torque demand. The approach only covers power circulation within a system with known system voltage. No initial architecture voltage derivation or components sizing was considered. A fixed motor voltage of $1000 \mathrm{~V}$ was used in [13], for the investigation of a hybrid electric propulsion system. It was shown that the system mass was optimized if the upstream components were adapted to variable voltages, to eliminate the voltage regulation devices. Also, that as the ratio of voltage to power increased, the total mass increased, while the efficiency decreased.

The reviewed voltage and current derivation approaches were based on components in isolation, superconducting technologies and battery powered aircrafts. They did not cover non-superconducting turboelectric aircrafts and also do not

demonstrate the influence of aircraft dimensions and thrust requirements on the derived operational voltage and current.

\section{Voltage Derivation}

The derivation of voltage and current presented here follows the motor demands, since its performance has the most impact on the reliability of the propulsion system. This approach proposes that the voltage of the motor driving the fan be imposed on the entire electrical system. Therefore, it begins with the knowledge of the speed and torque requirement and then a derivation of the motor flux linkage necessary to meet this demand. Fig. 2 shows the procedure for the modelling approach.

First, an aircraft size and a mission design point are selected (usually the point of maximum power demand), in order to properly estimate the propulsor size and power. Next, the motor sizing and dynamic performance, then other components sizing follows.

\section{A. Ducted Fan Modelling}

The modelling of the ducted fan is done to obtain the required power, rotations per minute (RPM) and diameter of the fan to deliver the needed thrust. The derived power and RPM become the rating of the electrical motor to drive the fan. This effects the aerodynamic and electrical coupling, save for the inclusion of a gearbox.

Fig. 3 is the flow chart representation of the procedure. This is actualized by considering the thermodynamic and aerodynamic characteristics of the air through the duct in five typical stages; freestream, inlet, duct stream (before and after 


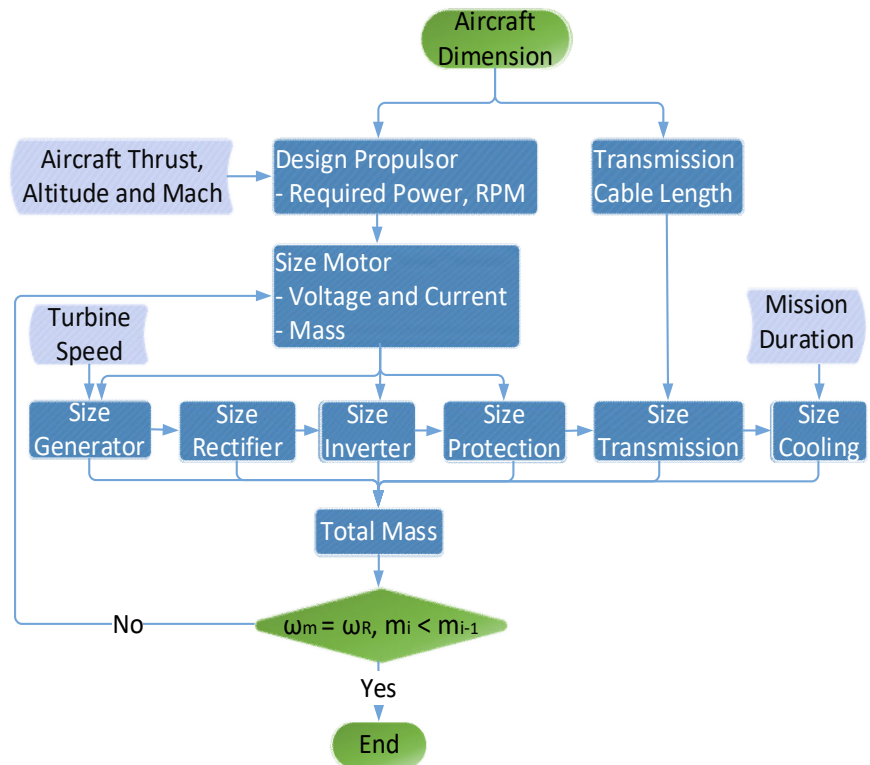

Fig. 2. Flow Chart of the Modelling Procedure.

the fan), and nozzle.

The net thrust $F_{n}$ produced by the ducted fan is expressed as (1)[20].

$$
F_{n}=\dot{m}\left(V_{8}-V_{0}\right)+A_{8}\left(p_{8}-p_{0}\right)
$$

Where $\dot{m}$ is the mass flow rate of the air into the duct, $V_{0}$ and $V_{8}$ are the freestream and exit velocities of the air, $A_{8}$ is the area of the nozzle while $p_{0}$ and $p_{8}$ are the static pressures of the freestream air and nozzle respectively. The power required to produce the net thrust is obtained as

$$
P=\dot{m} C_{p} \Delta T
$$

Where $C_{p}$ is the isobaric specific heat capacity of air and $\Delta T$ represents the difference between the total air temperature upstream and downstream of the fan. The procedure for deriving $\Delta T$ have been adopted from[20]. With the change in temperature across the fan derived, it is possible to obtain the fan RPM using

$$
R P M=\frac{\sqrt{\frac{C_{p} \Delta T}{L o a d}} \times 60}{2 \pi r_{f}}
$$

Where $r_{f}$ is the radius of the fan while Load is the fan stage loading coefficient. The mass of the fan is also required, for the computation of the total inertia load on the motor shaft. This will enable the consideration of transient performance in the design process. TABLE I shows a comparison between estimated fan parameters and published values from [21] for same aircraft.

From

(3) and TABLE I, it could be deduced that for a given maximum power and fixed fan diameter, operating the fan at a higher RPM

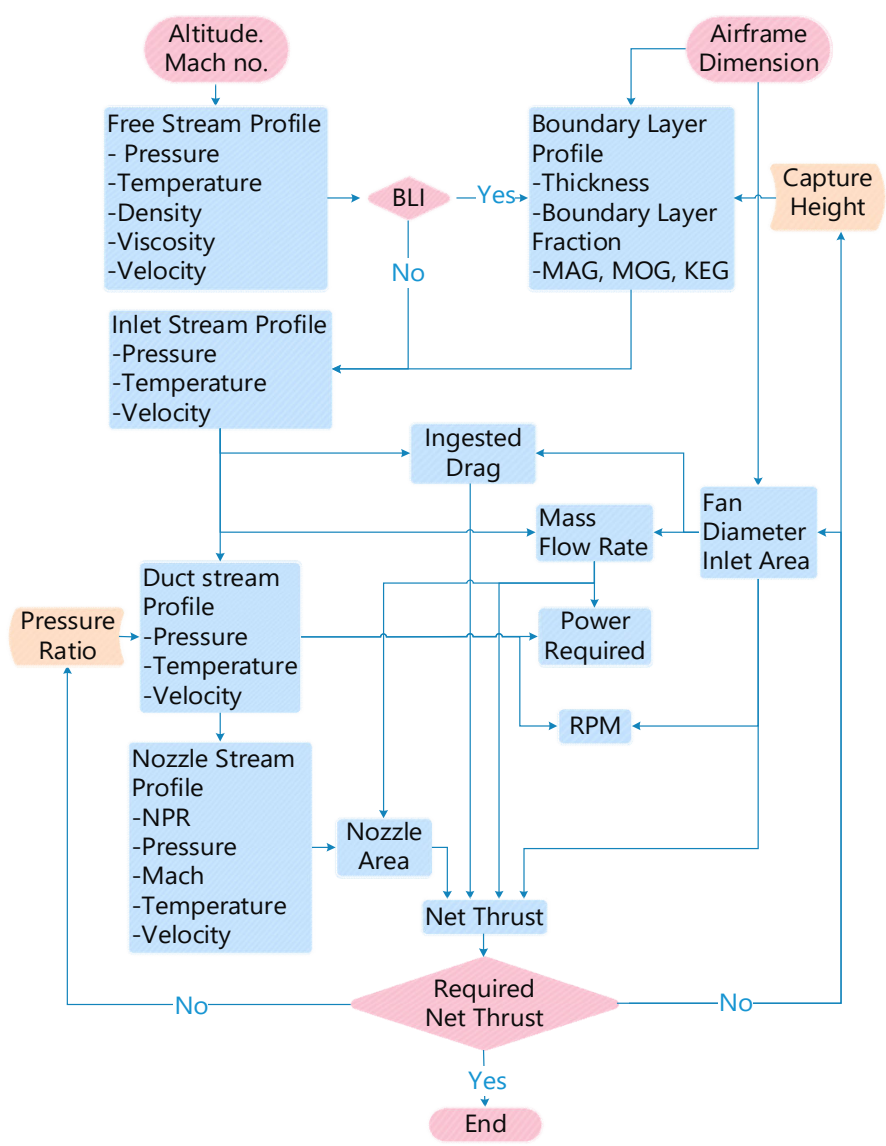

Fig. 3. Power and RPM Derivation Approach.

TABLE I

DUCTED FAN DESIGN VALIDATION

\begin{tabular}{lll}
\hline \hline Parameter & \multicolumn{1}{c}{ Published (SI Units) } & Estimated \\
\hline Net Thrust(lb) & $3210(14278)$ & $14009(\mathrm{~N})$ \\
Altitude(ft) & $37574(11453)$ & $11400(\mathrm{~m})$ \\
Power(hp) & $3500(2610000)$ & $2699859(\mathrm{~W})$ \\
Mach & 0.785 & 0.78 \\
Fan Pressure Ratio & 1.25 & 1.25 \\
Loading Coefficient & - & 0.39 \\
RPM & $1920^{\mathrm{a}}$ & 1911 \\
Fan Diameter(in) & $81(2.057)$ & 2.057 \\
Fan Mass(kg) & - & 358.7 \\
\hline \hline
\end{tabular}

a Take-off [41]

would require a lowering of the stage loading coefficient, subject to tip speed limits as shown in Fig. 4.

The graph in Fig. 4 represents 7 different propulsion system configurations, in which the rated speed of the fan is varied between 1500RPM to 6000RPM. It is generated, assuming isothermal operating condition across the fan. However, in reality this implies either a change in the fan configuration, ambient conditions, thrust or power. Therefore, the sizing of the motor would be required to cater for both the points of maximum power and selected maximum RPM, if they do not coincide. The typical load profile of such a fan is presented in Fig. 5 for a given thrust target and maximum power. 


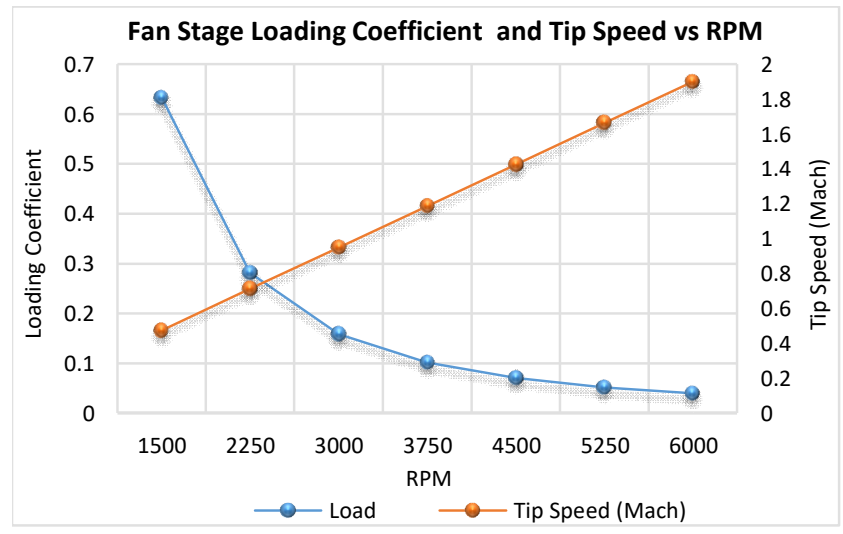

Fig. 4. Variation of Fan RPM at Different Loading.

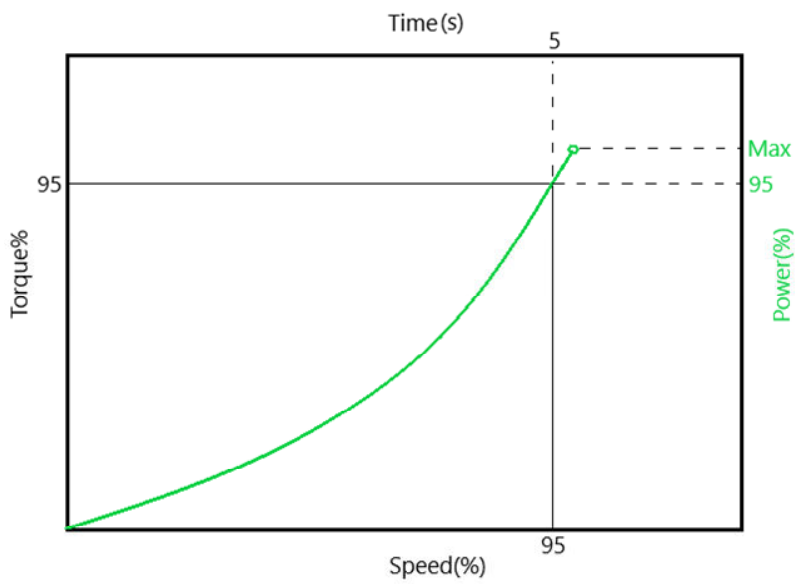

Fig. 5. Typical Torque-Speed Curve for the Ducted Fan.

The profile graph considers the aviation requirement for the propulsion system to be capable of delivering $95 \%$ of its rated thrust within 5s, from an idle scenario[22]. This requirement also needs to be considered in matching the motor to the fan.

\section{B. Electrical Machines Sizing}

Electrical machines refer to motors which convert electrical to mechanical power and generators which converts mechanical to electrical power. These are the main enablers for electrical propulsion. Electric machines currently deployed in small aircrafts propulsion are permanent magnet synchronous machines (PMSM) [23], [24]. These have also been proposed in [25][26] for future medium and large aircraft, due to their high specific power and minimal complexity. Thus, enabling them to be seamlessly deployed as motors or generators, by the application of voltage or torque respectively. Following this trend, a PMSM is considered for the sizing approach presented in this work.

Previous works [13], [25] on electrical machines design and sizing are predominantly analytic, requiring quantitative details at the start of design, like the number of slots, rotor size and some internal dimensions. The major challenge with such procedures is with the determination of required number of conductors (turns) per slot to achieve the target rating. This is due to several possible approaches for winding the machines, in pursuit of an optimal design. Accommodating the myriads of winding patterns is beyond the scope of this research, primarily because they are mostly required at the production stage. Other approaches[27] use specific power of the state-of-the-art (SOA) machines, which may not cater for individual design peculiarities like the ability to withstand transients and to deliver the required torque and speed. These requirements are also a product of voltage and current combination, which must be optimally selected as per design.

The design approach presented in this work is based on the torque capability, flux propagation, machine impedances and the interactions which occur between them in order to fulfil the required aerospace targets. These expresses the static (mass and volume) and dynamic (electromechanical) characteristics.

The flow chart in Fig. 6 shows the procedure for sizing the motor with an embedded voltage and current derivation. The approach also includes temperature consideration and a mass optimization loop.

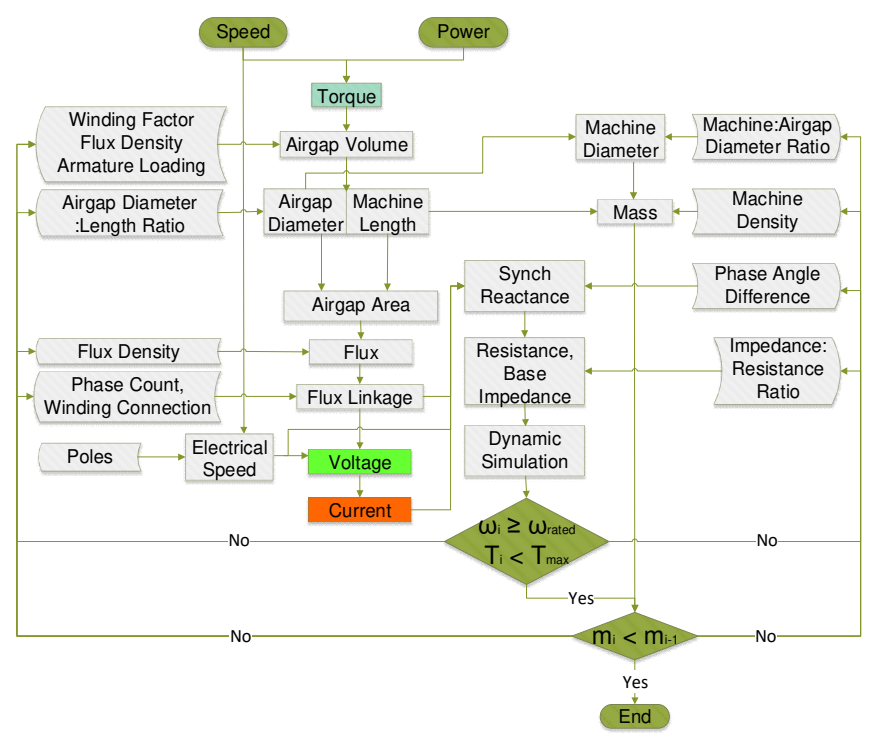

Fig. 6. Voltage and Current Selection Procedure.

The static characteristics of the motor is estimated based on the close relationship between the required power, speed and the volume comprising the airgap diameter. For internal rotor machines this diameter is referred to as the rotor diameter[17], [28], while for external rotor machines it is referred to as the stator outer diameter [29]. In this research, external rotor machines are considered, since the design principles presented are inferred from earlier presented machines proposed for aerospace applications[31], [32], which has same topology.

With known power and speed, the machine airgap volume $v_{A G}$ can be derived using

$$
v_{A G}=\frac{P_{m}}{\omega_{m} K_{w} B_{g} A_{L} \sqrt{2}}
$$

Where $K_{w}$ is the fundamental winding factor, $B_{g}$ is the airgap flux density (T), $A_{L}$ is the armature loading $(\mathrm{A} / \mathrm{m}), P_{m}$ and $\omega_{m}$ are the required motor power (W) and speed $(\mathrm{rad} / \mathrm{s})$ respectively. The importance of deriving the airgap volume of the machine is because of its influence on the flux propagation. The usual aim of optimized motor design, is to fit as much flux 
required to deliver a given power, in the smallest possible airgap. The airgap diameter of the machine $D_{A G}$ can be obtained using

$$
D_{A G}=\sqrt[3]{\frac{4 v_{A G} R_{D L}}{\pi}}
$$

The machine diameter $D_{M}$ is given by

$$
D_{M}=R_{M A G} D_{A G}
$$

The airgap area $A_{A G}$ is given by (7)[32]

$$
A_{A G}=\pi D_{A G} L
$$

The total airgap flux $\varphi$ and flux linkage per phase $\lambda$ can be obtained using (8) and (9) respectively.

$$
\begin{aligned}
& \varphi=B_{g} \times A_{A G} \\
& \lambda=\frac{\varphi}{N_{p h} k_{p h}}
\end{aligned}
$$

Where $R_{D L}$ is the airgap diameter-to-length ratio, $R_{M A G}$ is the machine-to-airgap diameter ratio, $L$ is the machine length, $N_{p h}$ and $k_{p h}$ are the number of phase and phase connection factor respectively. $k_{p h}$ is 1 for a delta connected winding and $\sqrt{3}$ for a wye connected winding.

The voltage of the motor and hence of the electrical network can be obtained using the induced voltage equation (10).

$$
V_{D e s}=\frac{\omega_{e} \lambda}{\sqrt{2}}
$$

Where $\omega_{e}$ is the electrical speed of the machine ( $\left.\mathrm{rad} / \mathrm{s}\right)$ given as

$$
\omega_{e}=2 \pi\left(\frac{R P M \times p_{S}}{120}\right)
$$

The bracket term represents the motor rated frequency, where $p_{S}$ is the stator pole count. It is important to state also, that the derived voltage is the RMS value for a motor, with delta internal winding connection. The obtained value should be multiplied by $\sqrt{3}$ for a wye connected winding.

With known voltage, current $I$ can be obtained using the electrical power equation as

$$
I=\frac{P_{m}}{V_{D e s}}
$$

In order to establish that the designed machine can deliver the required torque and speed, a matching of the static and dynamic characteristics is required. Equations (13) to (22) express the dynamic characteristics of the PMSM. The orthogonal components of the stator currents are represented by the direct axis current $I_{d}$ and quadrature axis current $I_{q}$. These are given by (13) and (14) respectively.

$$
\begin{gathered}
I_{d}=\int\left(\frac{-R_{S} I_{d_{-} i-1}+\left(\frac{\omega_{m} p_{S}}{2}\right)\left(L_{q} I_{q_{-} i-1}\right)+V_{d}}{L_{d}}\right) d t \\
I_{q}=\int\left(\frac{-R_{S} I_{q_{-} i-1}-\left(\frac{\omega_{m} p_{S}}{2}\right)\left(L_{d} I_{d_{-} i-1}+\lambda\right)+V_{q}}{L_{q}}\right) d t
\end{gathered}
$$

Where $V_{d}$ and $V_{q}$ are the $\mathrm{d}$ and $\mathrm{q}$ axis voltages obtained through an ABC-DQ transformation, $R_{S}$ is the stator resistance, $L_{q}$ and $L_{q}$ are the $\mathrm{d}$ and $\mathrm{q}$ axis inductances.

The inductance $L_{m}$ of the machine can be obtained using

$$
L_{m}=\frac{\sin \left(\frac{\emptyset \pi}{180}\right) \lambda}{I}
$$

Where $\varnothing$ is the phase angle (in degrees). The $\mathrm{d}$ and q axis inductances $L_{q}$ and $L_{d}$ are obtained with (16) and (17) respectively.

$$
\begin{gathered}
L_{q}=\left(\frac{2}{3}\right) L_{m} \\
L_{d}=\sqrt{L_{m}^{2}-L_{q}^{2}}
\end{gathered}
$$

The synchronous reactance $X_{s}$ and resistance $R_{s}$ are obtained using (18) and (19) respectively.

$$
\begin{aligned}
X_{s} & =L_{m} \omega_{e} \\
R_{s} & =\frac{X_{s}}{r_{X / R}}
\end{aligned}
$$

Where $r_{X / R}$ is the ratio of synchronous reactance to resistance.

The electromagnetic torque $T_{e}$ which does the electrical to mechanical power conversion and vice versa, is given by

$$
T_{e}=\frac{3}{2}\left(\frac{p_{s}}{2}\right)\left(\lambda I_{q}\right)+\left(L_{d}-L_{q}\right)\left(I_{q} I_{d}\right)
$$

While the machine mechanical speed is given by

$$
\omega_{m}=\int\left(\frac{T_{e}-T_{L}-B \omega_{m_{-} i-1}}{J}\right) d t
$$

Where $T_{L}$ is the load torque, $\omega_{m i}$ is the instantaneous speed, $J$ is the total inertia on the rotor, $B$ is the coefficient of viscous damping in the shaft bearings, while $\theta$ the angular displacement of the rotor from a reference point of rest is expressed as

$$
\theta=\left(\frac{p_{S}}{2}\right) \int\left(\omega_{m}\right) d t
$$

As already mentioned, a PMSM can also operate as a generator with the application of torque at the shaft rather than voltage at the cable terminals. The generator modelling follows similar procedure, using same equations as the motor modelling. However, because the motor voltage is imposed on all network components, the static equations are applied in reverse order from (11) to (4) in order to obtain the volume and 
then mass of the generator. The inner diameter is selected as the optimization handle, since the voltage is already known. The $R P M$ utilized for obtaining $\omega_{e}$ in this case is the turbine shaft speed driving the generator. Also, due to the reversal of power flow compared to the motor, (21) is rewritten as

$$
\omega_{m}=\int\left(\frac{\mathrm{T}_{\mathrm{e}}+\mathrm{T}_{\mathrm{L}}-\mathrm{B} \omega_{m \_i-1}}{\mathrm{~J}}\right) d t
$$

The inertia derivation for the generator only considers the rotor mass and dimensions.

The assumed ratios in (5), (6) and (19) can be derived using a scaling approach from existing machines, preferably the SOA. Fig. 7 shows the notional cross section of the considered machine. The concentric annuli from $i$ to $n$ respectively map to the machine housing, rotor shell, permanent magnets, windings, stator yoke, heatsink, ground cylinder and shaft.

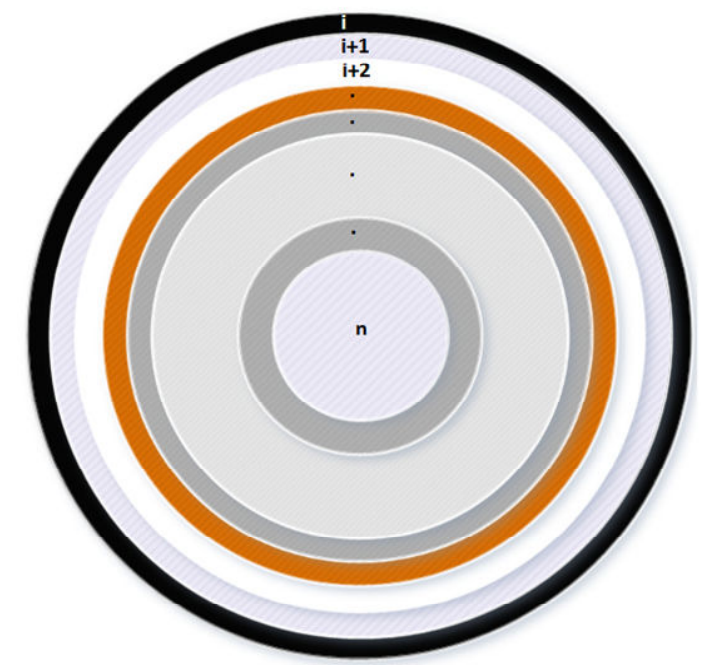

Fig. 7. Electrical Machine Cross Section.

The mass $m_{m}$ of the motor can be derived as a sum of the masses of all the constituent parts as

$$
\begin{aligned}
m_{m}=\left(\pi r_{n}^{2} L \rho_{n}\right) & +\left(\pi r_{i+1}^{2} \rho_{i+1}\right) \\
& +\left(\sum_{i=1}^{n-1} \pi\left(r_{i}^{2}-r_{i+1}^{2}\right) L \rho_{i}\right)
\end{aligned}
$$

Where, the first term represents the shaft mass, the second term represents the end plate mass while the third term represent the sum of the masses of the concentric annuli. $r$ in each case refers to the outer radius of the referred annulus, $\rho$ represents the density of the material constituting the referred annulus, while $L$ is the length of the machine. A hollow factor of 0.35 is considered for the heatsink layer to account for the air channel included.

For such external rotor topology, three main mechanical challenges are identified; the rotor radial expansion, installation feasibility and load transmission. In [31], the structural analysis and installation feasibility for such motor topology was performed. It was proposed to be installed by fastening the base structure to the aircraft, for a reliable transmission of the thrust to the aircraft. In order to achieve radial expansion integrity, the motor housing thickness should be selected with due consideration of the tip speed at the magnet external radius $V_{t i p}$ [33] and allowable temperature change $\Delta T$ of the permanent magnets beneath. This can be obtained using

$$
T_{H}=\frac{V_{t i p} \rho_{m}}{2 r_{o} \Delta T \alpha E}\left(r_{o}{ }^{2}-r_{i}{ }^{2}\right)
$$

Where $\rho_{m}$ and $\alpha$ are the density and linear expansion coefficient of the magnetic material respectively, $r_{o}$ and $r_{i}$ are respectively the outer and inner radius of the annulus comprising the magnets while $E$ is the Young's modulus of the motor housing material.

To ensure that the machines are operating within their maximum allowable temperature, thermal consideration is also performed. This depends on the efficiency and heat capacity of the machine components. In [33], it was stated that the stator winding has the most susceptibility to heat, due to being enclosed while directly handling the machine electrical power. The stator maximum temperature is the sum of the ambient temperature and temperature change due to the losses given by

$$
T_{M}=T_{A m b}+P_{L} R_{t h \_} W
$$

Where $T_{A m b}$ is the ambient temperature, $R_{t h \_W}$ is the thermal resistance of the winding while $P_{L}$ is the power loss in the winding given by

$$
P_{L}=I^{2} R_{w}+V I_{0}
$$

$I$ is the machine current, $R_{w}$ is the winding resistance, $V$ is the machine voltage while $I_{0}$ is the machine no load current. Assuming an air-core stator, the thermal resistance of the winding layer is given by

$$
R_{t h \_W}=\frac{\ln \left(\frac{r_{A G}}{r_{S}}\right)}{2 \pi L k_{W}}
$$

Where $r_{A G}$ is the airgap radius, $r_{S}$ is the radius of the stator, $L$ is the active length of the machine while $k_{W}$ is the thermal conductivity of the winding. The cooling method for such motor topology have been adopted from [33], where forced air convection has been deployed with the inclusion of a heatsink annulus beneath the stator. Fig. 8 shows a comparison of the values obtained using the presented approach, with published data in [30] for a machine proposed for aerospace applications.

\section{Power Electronics Sizing}

Power electronics devices proposed for aerospace propulsion include rectifiers, inverters, voltage regulators, and circuit protection devices. They are comprised of semiconductor-based switches, integrated circuits, inductors and capacitors. The main design principles utilized in this paper have been adopted from already validated device models in [34] and [35]. These models based the sizing and performance of the devices on six functional components; the switches, capacitors, gate drivers, controllers, bus bars and support structures. 


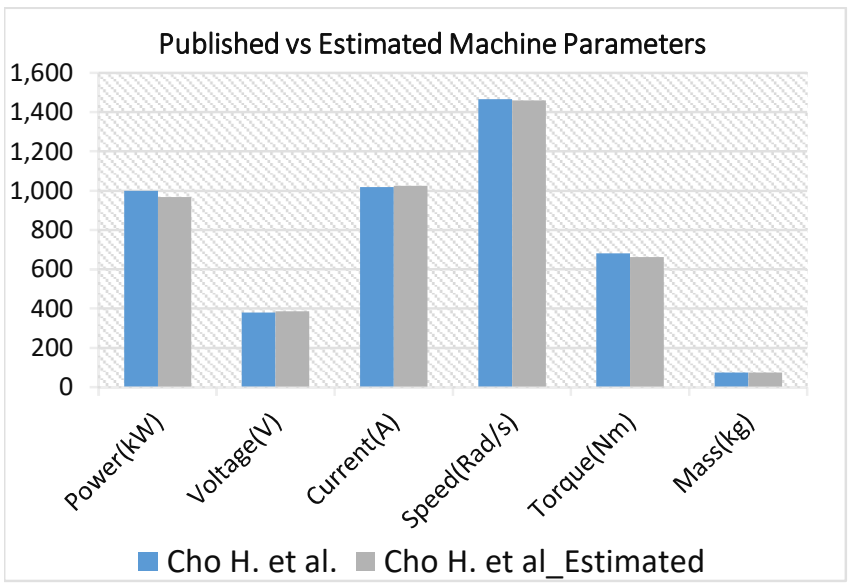

Fig. 8. Electrical Machine Sizing Validation.

Switch adopted in this work is the more efficient silicon carbide metal-oxide-semiconductor field-effect transistor ( $\mathrm{SiC}$ MOSFET). Their selection is reliant mostly on the current and voltage handling limits. SOA is considered, to reflect the improved power density of the currently available switches. Hence the mass of each switch is obtained from manufacturer database. However, the efficiency of these switches depend on the operating currents and voltages. This is a function of the switching device power loss, given by

$$
P_{S}=P_{T}+P_{D}
$$

Where $P_{T}$ and $P_{D}$ are the switching transistor and diode losses respectively. These are given by (30) and (31)[36] respectively.

$$
\begin{gathered}
P_{T}=I_{R M S}^{2} R_{D S_{-} O N}+f_{S w} E_{S w} \\
P_{D}=I_{F_{-} a v} V_{F 0}+I_{R M S}^{2} R_{F}+f_{s w} E_{R e c}
\end{gathered}
$$

Where, $I_{R M S}$ is the RMS value of the input current to the device, $R_{D S_{-} O N}$ is the drain-source on-state resistance of the switch, $I_{F_{-} a v}$ is the average value of the current through the diode, $V_{F 0}$ is the diode on-state zero-current voltage and $R_{F}$ is the resistance of the diode. $f_{S W}$ is the switching frequency while $E_{s w}$ and $E_{R e c}$ are the switching and recovery energies in the transistor and diode respectively. $E_{R e c}$, can be obtained using

$$
E_{\text {Rec }}=\frac{\left(Q_{r r} \times V_{D}\right)}{4}
$$

Where $Q_{r r}$ is the reverse recovery charge and $V_{D}$ is the supply voltage. TABLE II shows the design parameters of the switch adopted in this work.

Capacitors modelled here are the DC link capacitors. In order to obtain the appropriate size, the capacitance required to filter a given voltage ripple value is derived using (33)[16].

$$
C=\frac{I_{D C}}{2 f_{A C} \Delta V_{D C}}
$$

Where $I_{D C}$ is the DC current, $\Delta V_{D C}$ is the DC voltage ripple and $f_{A C}$ is the supply frequency.
TABLE II

SELECTED SWITCH SPECIFICATIONS

\begin{tabular}{ll}
\hline \hline Parameter & Value[42] \\
\hline Rated Voltage $\boldsymbol{V}_{D S S}(\mathrm{~V})$ & 1200 \\
Maximum Voltage $\boldsymbol{V}_{\text {isol }}(\mathrm{V})$ & 4000 \\
Rated Current $\boldsymbol{I}_{D}(\mathrm{~A})$ & 523 \\
Maximum Current $\boldsymbol{I}_{\boldsymbol{D M}}(\mathrm{A})$ & 1280 \\
Drain-source on-state resistance $\boldsymbol{R}_{\boldsymbol{D S} \text { _o }}(\Omega)$ & 0.0056 \\
Diode Resistance $\boldsymbol{R}_{\boldsymbol{F}}(\Omega)$ & 0.0045 \\
Diode on-state zero-current voltage $\boldsymbol{V}_{\boldsymbol{F} \mathbf{0}}(\mathrm{V})$ & 0.95 \\
Switching energy $\boldsymbol{E}_{\boldsymbol{s} \boldsymbol{W}}(\mathrm{J})$ & 0.01663 \\
Reverse recovery charge $\boldsymbol{Q}_{\boldsymbol{r r}}(\mathrm{nC})$ & 330 \\
Mass $(\mathrm{g})$ & 325 \\
\hline \hline
\end{tabular}

The total power loss of the capacitor is given by

$$
P_{C}=P_{D}+P_{R}
$$

Where $P_{D}$ is the dielectric power loss and $P_{R}$ is the resistive power loss. These are given by (35) and (36)[37] respectively.

$$
\begin{gathered}
P_{D}=\left(0.1 V_{D C}\right)^{2} \cdot \pi \cdot f_{0} \cdot C \cdot \tan \delta_{0} \\
P_{R}=I^{2} \times R_{S}
\end{gathered}
$$

Where, $f_{0}$ is the fundamental frequency and $\tan \delta_{0}(2 \mathrm{e}-4)$ is the dielectric dissipation factor. TABLE III shows the operational parameters of the capacitor adopted for this work.

TABLE III

SELECTED CAPACITOR SPECIFICATIONS

\begin{tabular}{ll}
\hline \hline Parameter & Value[43] \\
\hline Capacitance $(\mu \mathrm{F})$ & 560 \\
Voltage DC(V) & 700 \\
Current $(\mathrm{A})$ & 80 \\
Maximum current(A) & 8000 \\
$R_{S}(\mathrm{~m} \Omega)$ & 1.1 \\
$\operatorname{Mass}(\mathrm{g})$ & 880 \\
\hline \hline
\end{tabular}

The other components that constitute the power electronics are sized using a mass scaling factor $\mathrm{m}_{k}$. This is multiplied by the switch count, since these components are auxiliaries of the switching process. TABLE IV shows data for the four converters considered for this derivation. A low power bench test converter is added to the initially referenced converters. The New mass refers to the converter mass excluding the capacitor and all cooling accessories, since they are sized separately. The scaling factor obtained for each converter, expresses the ratio of the New mass to the total switch mass. A value of 9.1 is obtained as the mass scaling factor for all switching devices, which includes the rectifier, inverter and protection devices. These are modelled next.

\section{1) Rectifier Sizing}

The rectifier acts to convert the alternating current (AC) from the generator to direct current (DC), to enable it to be controlled. Modern high-power rectifier circuits are often implemented using solid state switches. Fig. 9 shows a typical rectifier configuration. 
TABLE IV

MASS SCALING FACTOR DATA

\begin{tabular}{|c|c|c|c|c|}
\hline Parameter & $\begin{array}{l}\text { Test } \\
\text { Converte } \\
\mathrm{r}\end{array}$ & $\begin{array}{l}\text { X. Ding } \\
\text { et al[34] }\end{array}$ & $\begin{array}{l}\text { CRD300 } \\
\text { DA12E- } \\
\text { XM3[38] }\end{array}$ & $\begin{array}{l}\text { D. } \\
\text { Zhang } \\
\text { et al }[44]\end{array}$ \\
\hline Power(kW) & 0.36 & 30 & 300 & 1000 \\
\hline Total mass $(\mathrm{g})$ & 77.3 & 16900 & 6200 & 98000 \\
\hline Switch Count & 6 & 3 & 3 & 18 \\
\hline Total Switch mass(g) & 11.4 & 900 & 525 & 6210 \\
\hline Capacitor mass(g) & 3 & 900 & 1230 & - \\
\hline Heatsink mass(g) & 3.6 & $5238.78^{a}$ & 1082 & $6000^{\mathrm{a}}$ \\
\hline Cooling fan $(\mathrm{g})$ & 0 & 0 & 62.14 & - \\
\hline New mass(g) & 59.3 & 9861.22 & 3300.86 & 85790 \\
\hline Scaling factor & 5.201 & 10.957 & 6.287 & 13.8 \\
\hline
\end{tabular}

${ }^{\mathrm{a}}$ Estimated

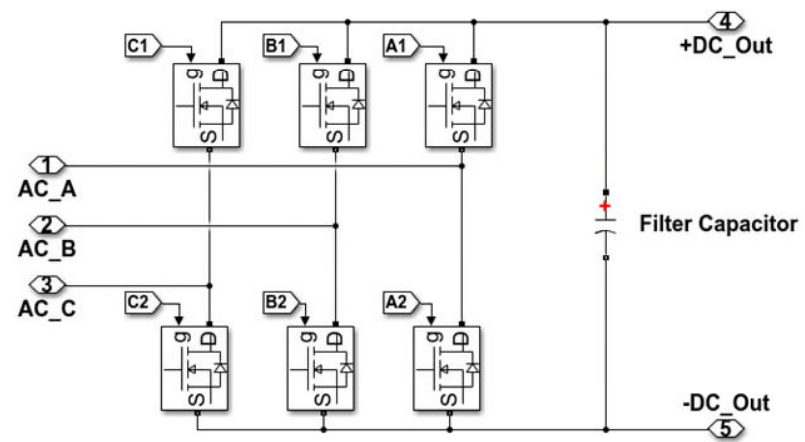

Fig. 9. Typical Rectifier Circuit Configuration.

The in-ports $1-3$ are for the three phases of AC voltage output from the generator. The out-ports 4 and 5 are the positive and negative DC terminals respectively. The filter capacitor smoothens the output of the switches to improve the power quality. The rectification is performed based on a preset design value (system design voltage), by sending switching control signals to the respective switches using signaling ports A1 through $\mathrm{C} 2$. Other supporting components include the heatsinks, other cooling devices and mounting accessories.

The total mass of the rectifier is derived using

$$
\mathrm{m}_{\text {Rec }}=\mathrm{m}_{S} C_{S_{-} R e c} \mathrm{~m}_{k}+\mathrm{m}_{C} C_{C_{-} R e c}
$$

Where $m_{S}$ and $m_{C}$ are the unit masses of the switching device and the capacitor respectively, while $C_{S_{-} R e c}$ and $C_{C_{-} R e c}$ are their respective total counts. These are derived using (38) and (39) respectively.

$$
\begin{gathered}
C_{S_{-} R e c}=\left\lceil\frac{\mathrm{V}_{\text {Des }}}{\mathrm{V}_{\text {max_S }_{\_}}}\right\rceil \times\left\lceil\frac{\mathrm{I}_{\text {Des }}}{\mathrm{I}_{\text {max }_{-} \mathrm{S}}}\right\rceil \times 6 \\
C_{C_{-} R e c}=\left\lceil\frac{\mathrm{V}_{\text {Des }}}{\mathrm{V}_{\text {max }_{-}}}\right\rceil \times\left\lceil\frac{\mathrm{I}_{\text {Des }}}{\mathrm{I}_{\text {max }_{-}}}\right\rceil
\end{gathered}
$$

$\mathrm{m}_{k}$ is a multiplier, to account for the mass of the circuit board and support structures, and hence is the switch mass scaling factor. $V_{\text {Des }}$ and $I_{\text {Des }}$ are the system design voltage and currents respectively, $V_{\text {max_s }}$ and $I_{\text {max_s }}$ are respectively the voltage and current handling limit of the switch, while $\mathrm{V}_{\text {max }_{-} \mathrm{C}}$ and $\mathrm{I}_{\text {max }} \mathrm{C}$ are respectively the voltage and current handling limit of the capacitor. $\mathrm{I}_{\mathrm{Des}}$ here refers to the maximum surge current during motor transients. This could be obtained by putting (20) into (21) and solving for $I_{q}$, considering the transient duration.

The efficiency of the rectifier is obtained using

$$
\eta_{R e c}=1-\frac{\left(\mathrm{P}_{S} \frac{2 C_{S_{-} R e c}}{6}+\mathrm{P}_{C} C_{C_{-} R e c}\right)}{\mathrm{P}_{\mathrm{in}}}
$$

Where $\mathrm{P}_{\text {in }}, \mathrm{P}_{S}$ and $\mathrm{P}_{C}$ are the input power, power loss of one switch and capacitor respectively. In normal operation, only 2 switching channels are delivering power at a time, and hence contribute to the instantaneous loss of efficiency of the device.

\section{2) Inverter Sizing}

The inverter performs the speed control of the motor using one of several available techniques. However, common techniques exploit the relationship between current, motor inductance and flux, by means of pulse width modulation (PWM). Fig. 10 shows a typical inverter configuration. The inports 1 and 2 connect to the DC source while out-ports 1,2, and 3 are connected to the three phases of the motor. Ports A1 through $\mathrm{C} 3$ are the PWM control signals channel.

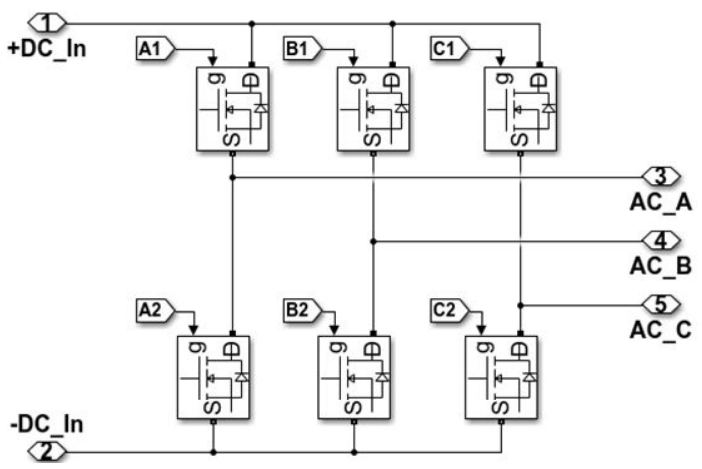

Fig. 10. Typical Inverter Circuit Components.

The mass and switch count of the inverter is derived by (41) and (42) respectively.

$$
\begin{gathered}
\mathrm{m}_{I n v}=\mathrm{m}_{S} C_{S_{-} I n v} \mathrm{~m}_{k} \\
C_{S_{-} I n v}=\left\lceil\frac{\mathrm{V}_{\text {Des }}}{\mathrm{V}_{\text {max_S }}}\right\rceil \times\left[\frac{\mathrm{I}_{\text {Des }}}{\left.\mathrm{I}_{\text {max_S }}\right\rceil \times 6}\right.
\end{gathered}
$$

The efficiency $\eta_{I n v}$ of the inverter is given by

$$
\eta_{I n v}=\left(1-\frac{\mathrm{P}_{S} \frac{2 C_{S_{I} I n v}}{6}}{\mathrm{P}_{\mathrm{in}}}\right)
$$

Where $C_{S_{-} I n v}$ is the switch count comprising the inverter while $\mathrm{P}_{S}$ is the power loss of a single switch and $\mathrm{m}_{k}$ is the switch mass scaling factor. The $I_{D e s}$ here refers to either the maximum surge current for the motor transient or the set fault current between the motor and the inverter. This is because the inverter drive is proposed to perform both the motor speed control and fault protection functions, based on experiments conducted in[36]. 


\section{3) Protection Sizing}

The protection device helps to isolate its principal device from faults occurring upstream or downstream of it. This can be achieved by limiting the magnitude of the current passing through, or by completely blocking off the flow, resulting in device unavailability. Two types of protection devices are considered: the AC circuit and DC circuit protection devices. The total protection system mass would depend on how many of such devices are deployed. This should vary by aircraft configuration. The mass of the protection system $\mathrm{m}_{P}$ deployed per channel at a given point is derived by

$$
\mathrm{m}_{P}=\mathrm{m}_{V} C_{V}+\mathrm{m}_{S} C_{S} \mathrm{~m}_{k}
$$

Where $\mathrm{m}_{V}$ is the mass of the varistor, $\mathrm{m}_{k}$ is the switch mass scaling factor and $C_{V}$ is the varistor count, given by

$$
C_{V}=\left\lceil\frac{\mathrm{V}_{- \text {Fault }}}{\mathrm{V}_{\text {max_V }}}\right\rceil \times\left\lceil\frac{\mathrm{I}_{- \text {Fault }}}{\mathrm{I}_{\text {max_V }}}\right\rceil
$$

Where $V_{\text {max_v }}$ and $I_{\text {max }} v$ are the varistor surge voltage and current arresting capability respectively. $C_{S}$ is the switch count comprising the protection device, given by

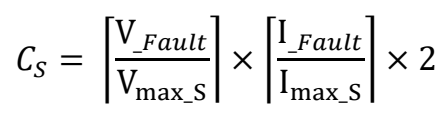

The $\mathrm{I}_{\text {Fault }}$ here also considers the maximum surge current or the set fault current, whichever gives the higher number, since switches have different current ratings for normal, surge and short circuit operation. The RC snubber circuit is not sized separately since it is accounted as part of the mass scaling factor $\mathrm{m}_{k}$, based on the design presented in [35], [38]. Based on same principle, it is seen that the value of fault voltage $\mathrm{V}_{\text {Fault }}$ can be kept at 1.2 times the rated DC equivalent. The sized protection system is per channel. Therefore, when deployed on a DC line only one is required. However, for a three-phase line, all three channels have one device each, since each channel carries both positive and negative voltages in alternating manner.

\section{Transmission Sizing}

The transmission system is sized in terms of the length, operating temperature limit and connection type. For DC and $\mathrm{AC}$ segments of the transmission lines, the interconnection would require two cables and three cables respectively. The cable comprises of a conductor core, an insulation layer and an exterior sheath layer. The minimum radius of the conductor is expressed as

$$
r_{C}=\sqrt{\frac{P_{\text {Rated }}\left(1-\eta_{C}\right)}{\left(T_{\text {max }}-T_{A m b}\right) \pi \rho_{C} C_{p_{-} C}}}
$$

Where $P_{\text {Rated }}$ is the rated power through that segment, $T_{\max }$ is the maximum allowable transmission cable temperature, $\mathrm{y}_{C}$ is the efficiency of the transmission cable, $\rho_{C}$ and $C_{p_{-} C}$ are the density and specific heat capacity of the transmission core material respectively.
With known core radius, the mass of the transmission cable of a given length, can be derived using

$$
m_{T}=v_{C} \rho_{C}+v_{i n s} \rho_{i n s}+v_{s h} \rho_{s h}
$$

Where $v_{C}$ and $\rho_{C}$ are the volume and density of the conductor respectively, $v_{\text {ins }}$ and $\rho_{\text {ins }}$ are those of the insulation material, while $v_{s h}$ and $\rho_{s h}$ are those of the sheath material.

The efficiency of the cable is obtained by

$$
\eta_{C}=\frac{I_{C} V_{C}-I_{C}^{2}\left(R_{C}+X_{C}\right)}{I_{C} V_{C}}
$$

Where $V_{C}$ and $I_{C}$ are respectively the transmission voltage and current while $R_{C}$ and $X_{C}$ are the resistance and inductive reactance of the transmission line respectively. $X_{C}$ is ignored for DC segments of the transmission line.

\section{E. Cooling Sizing}

The cooling requirement of the power electronics is based on the power loss and upper temperature limit of the cooled devices. The upper temperature limit of the device is given by

$$
T_{J}=T_{A m b}+P_{L}\left(R_{J S_{-} D}+R_{C S}\right)
$$

Where $T_{A m b}$ is the ambient temperature, $P_{L}$ and $R_{J S_{-} D}$ are respectively the maximum power loss and junction-to-sink thermal resistance of the cooled device, while $R_{C S}$ is the thermal resistance of the cooling system. Apparently, the most adjustable parameter with which to keep the value of $T_{J}$ below its maximum is $R_{C S}$. Therefore, the ultimate goal of the cooling system sizing is to achieve a low $R_{C S}$ value with minimum mass penalty. $R_{C S}$ can be estimated using

$$
R_{C S}=\left(\frac{1}{h A_{E}}\right)+\left(\frac{1}{\rho_{f} C_{p_{-} \dot{V}}}\right)
$$

Where $h$ and $A_{E}$ are respectively the heat transfer coefficient and exposed surface area of the cooling plate attached to the cooled device while, $\rho_{f}, C_{p_{-} f}$ and $\dot{V}$ are respectively the density, specific heat capacity and volumetric flow rate of the cooling fluid flowing across the cooling plate. The mass of the cooling system is given by

$$
m_{C}=m_{T P}+m_{T f}+m_{T A}
$$

Where $m_{T P}$ is the total mass of the cooling plate, $m_{T f}$ is the total mass of the cooling fluid while $m_{T A}$ is the total mass of the accessories required for implementing the cooling system. The cooling method adopted in this work is an extension of methods earlier presented in [39]. However, this utilizes the ducted fan's ram air as the cooling fluid, taking advantage of its force velocity while avoiding extra cooling fluid and accessory mass. Hence, a finned cooling plate is deployed, whose heat transfer coefficient is derived using methods presented in [40]. 


\section{RESUlts/Discussion}

This section presents and discusses the results of the proposed approach. These have been implemented using a tool developed on Matlab-Simulink. As already highlighted, the derivation of optimal voltage needs to be tailored to an aircraft and design point(s). The propulsive fuselage airframe concept shown in Fig. 11 (adapted) is selected, because of the availability of enough background literature.

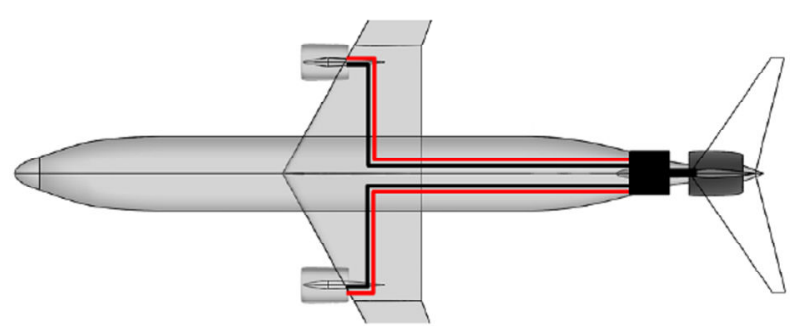

Fig. 11. The Propulsive Fuselage Aircraft Concept[11].

Fig. 12 shows the layout of electrical components for the proposed aircraft concept. The comprising devices are the generator (GEN), transmission (TXN), rectifier (REC), circuit breaker (CB), inverter (INV) and motor (MOT). The power flow is in the direction of the arrows, from the wing mounted generators, through the bus bar to the motor driving the tail fan.

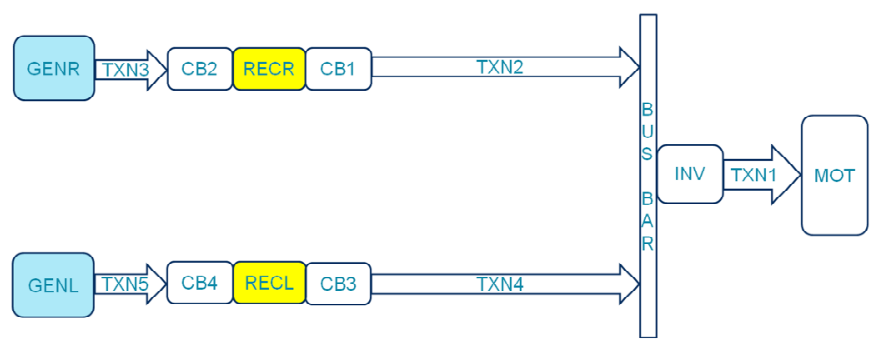

Fig. 12. Electrical Layout of the Considered Aircraft.

Fig. 13 shows the obtained voltages and currents for the range of RPM shown in Fig. 4.

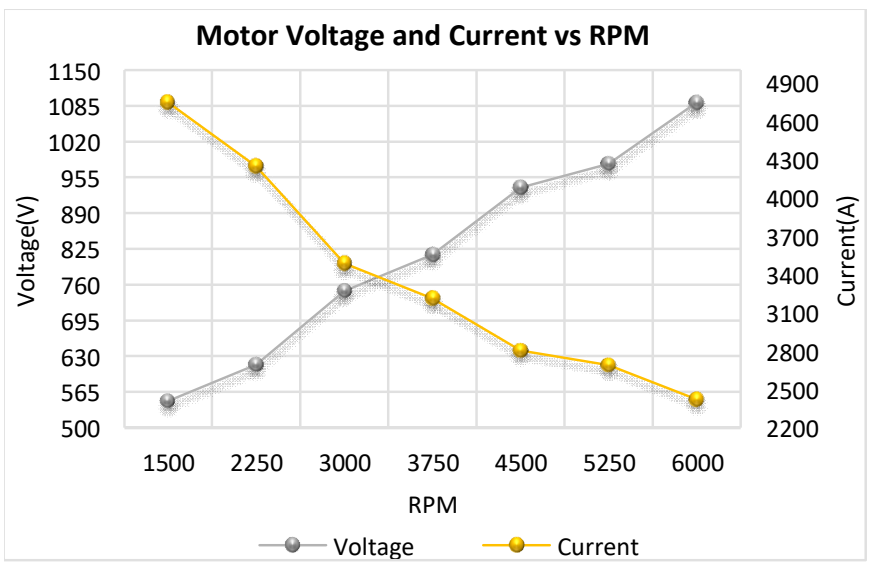

Fig. 13. Motor Current and Voltage vs RPM.

It is observable that the derived range of voltage is above the safe limit of breakdown voltage $(327 \mathrm{~V})$ due to gap and surrounding air pressure. However, the single conductor transmission cable modelled earlier, offers the opportunity to install the cables considering safe gaps between them. Also, the voltage is seen to almost double, over the range of RPM investigated. The inverse variation of current with increasing RPM occurs at a slightly lower rate compared to voltage.

The total system mass and efficiencies at these voltages and currents, is presented in relation to the motor speeds in Fig. 14.

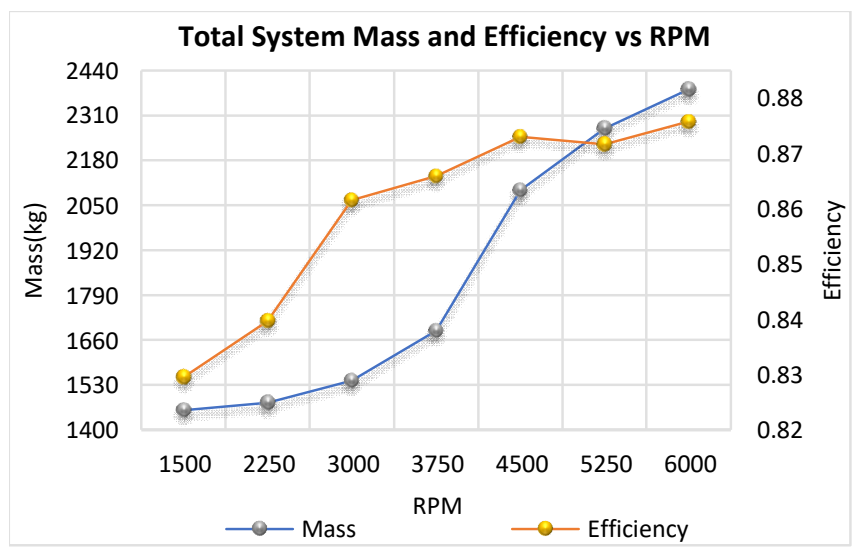

Fig. 14. Total System Mass and Efficiency.

From the graph, it could be seen that the point of optimal mass is at 1500RPM. This does not coincide with the point of optimal efficiency at 6000RPM. However, considering boundaries of tip speed, stage loading coefficient and the specific fuel consumption of the turbines, a suitable RPM and the corresponding voltage and current could be selected as optimal.

Fig. 15 shows the contribution of the system components to the total system mass. The masses of the devices which appear as twin in Fig. 12 has been presented as a sum of the two, with the assumption that they each handle equal power always. The main mass contributors are the electric machines due to their high torque requirement, as a direct drive without gearboxes have been considered. While the motor's mass varies inversely with its speed, the generator's mass varied directly. The generators speed is held at 4200RPM, governed by the turbine shaft speed. Therefore, with increasing system's voltage, larger airgap area is required, leading to bigger and heavier machine. Other devices exhibit a direct proportionality in their mass variation with increasing motor RPM. The DC transmission segment (TNX2) also has a noticeable mass contribution, owing to its longer span of $74 \mathrm{~m}$ total, compared to the AC segments (TXN1 and TXN3) which is a total of $6 \mathrm{~m}$. It is also noticeable that at lower RPMs, the systems mass tracks the motor and cooling mass, while the power electronics devices begin to have more significant contribution as the RPM increases.

Fig. 16 shows the percentage contribution of each component to the overall systems mass. The direct proportionality between power electronics mass and increasing RPM is due to significant increase in switch counts to cater for the transient currents. The transient current rise is due to the motor needing the capability to accelerate the fan to near maximum speed within 5s. The surge in current to meet this regulatory requirement rises significantly as rated fan speed increases.

Fig. 17 shows the efficiency of the devices at the various 

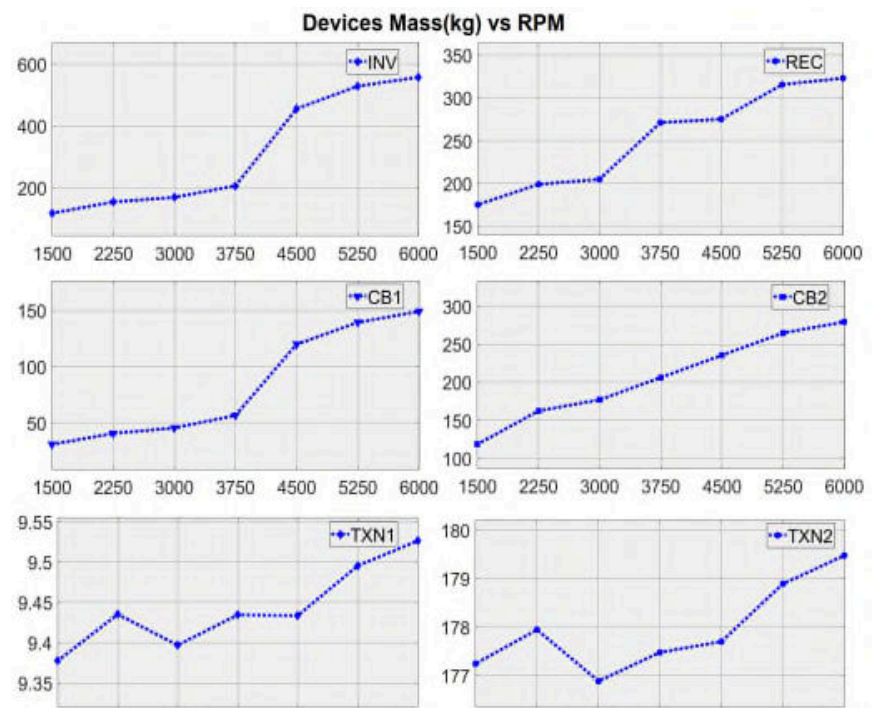

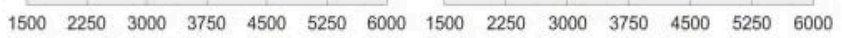
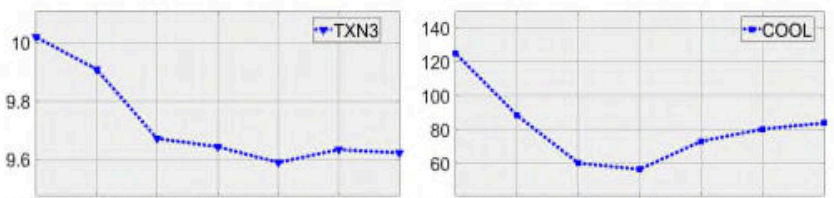

$\begin{array}{llllllllllllll}1500 & 2250 & 3000 & 3750 & 4500 & 5250 & 6000 & 1500 & 2250 & 3000 & 3750 & 4500 & 5250 & 6000\end{array}$
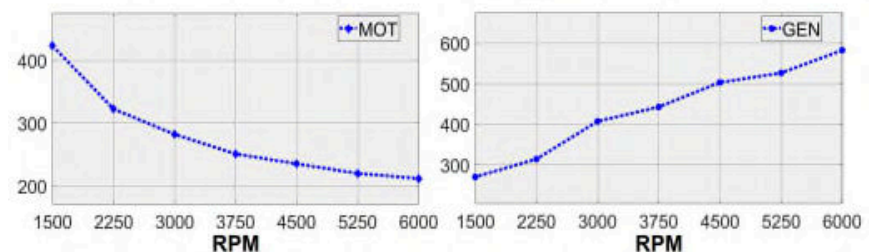

Fig. 15. Component Level Mass Breakdown.

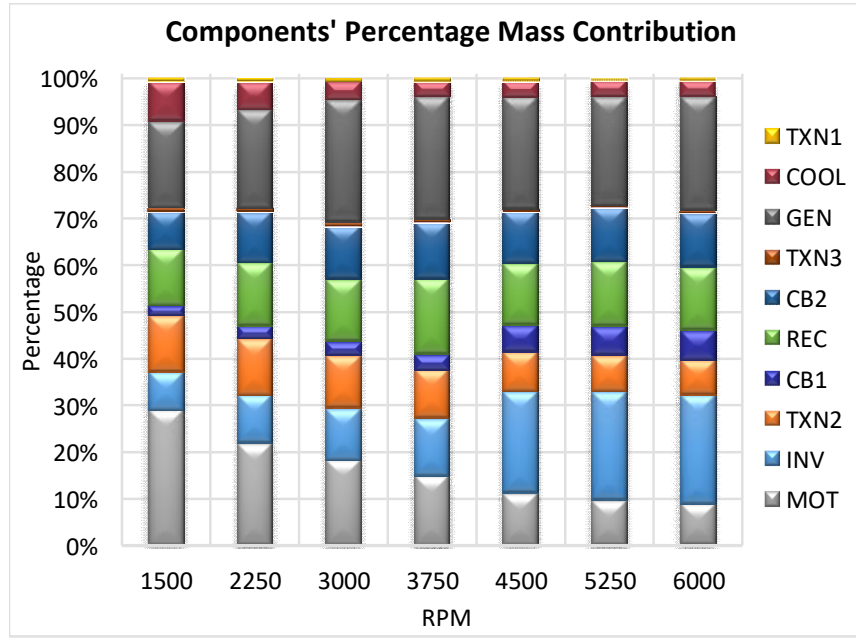

Fig. 16. Components' Percentage Mass Contribution.

motor speed configurations. The power electronics devices exhibit the highest efficiencies, while the electric machines and $\mathrm{AC}$ transmission segments contribute the most losses. The DC transmission segment have lower losses despite a longer span, due to the absence of alternating components. The cooling efficiency represents the efficiency of the fins on the cooling
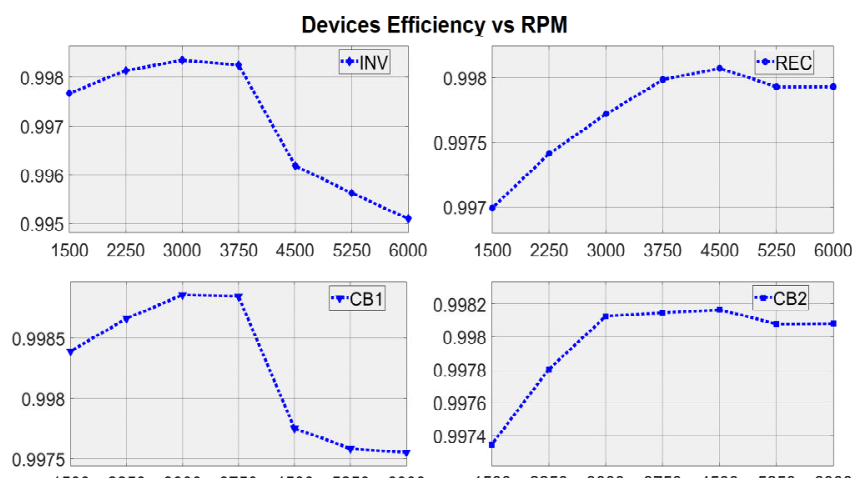

$\begin{array}{llllllllllllll}1500 & 2250 & 3000 & 3750 & 4500 & 5250 & 6000 & 1500 & 2250 & 3000 & 3750 & 4500 & 5250 & 6000\end{array}$
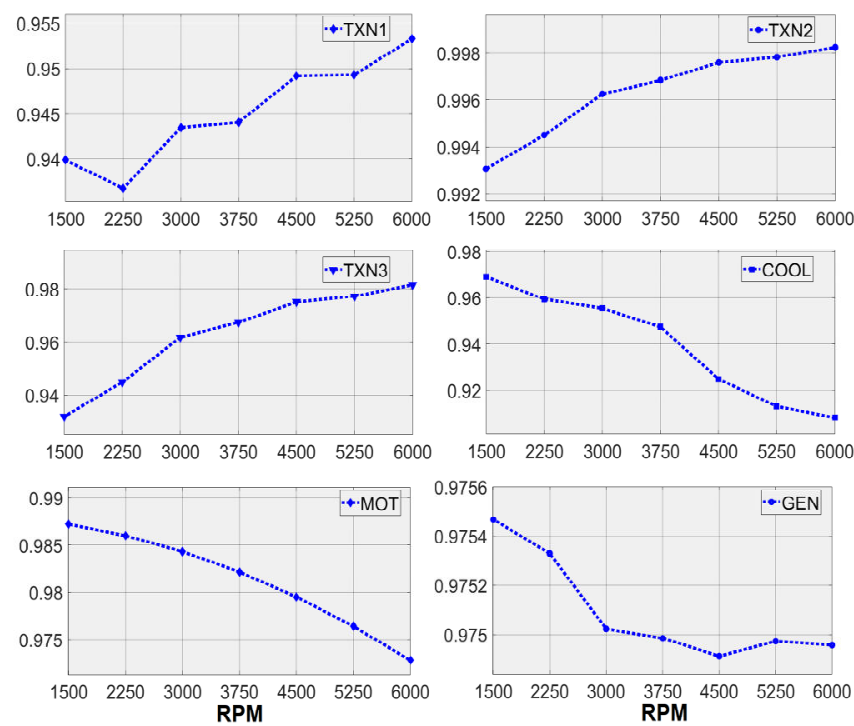

Fig. 17. Components Efficiency Profile.

plate and unlike other components' efficiency, only considers the power dissipated into it and not the total propulsion system power.

Fig. 18 shows the maximum temperature change of the machines for the various architectures. The trend for the motor is seen to rise with increasing speed due to lesser efficiency and heat capacity due to decreasing size. This trend reverses for the generator due to increasing size.

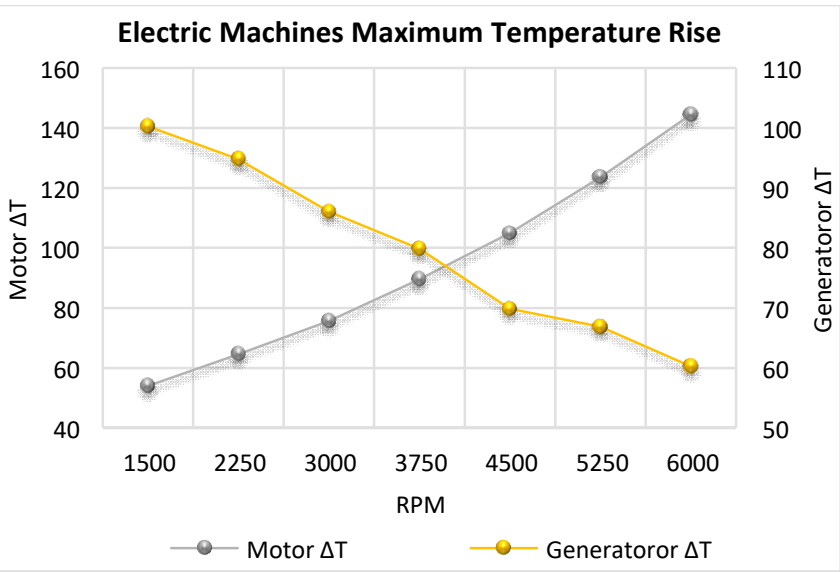

Fig. 18. Electrical Machines Maximum Temperature Increase. 
Fig. 19 shows a comparison of published values of components' mass and efficiency in [27]. The point of optimal mass is selected to match the sizing approach in the referenced literature. This is at 1500RPM with corresponding voltage and current of $549(\mathrm{~V})$ and $4746(\mathrm{~A})$ respectively. The derived masses are seen to be in a close range for a majority of the devices except the motor and cooling system mass. In terms of efficiency, only the transmission system shows significant deviation. As mentioned before, this is traceable to the AC segments. The difference between the total mass derived and the referenced is about $63 \mathrm{~kg}$ while that for the efficiency is about $6 \%$.

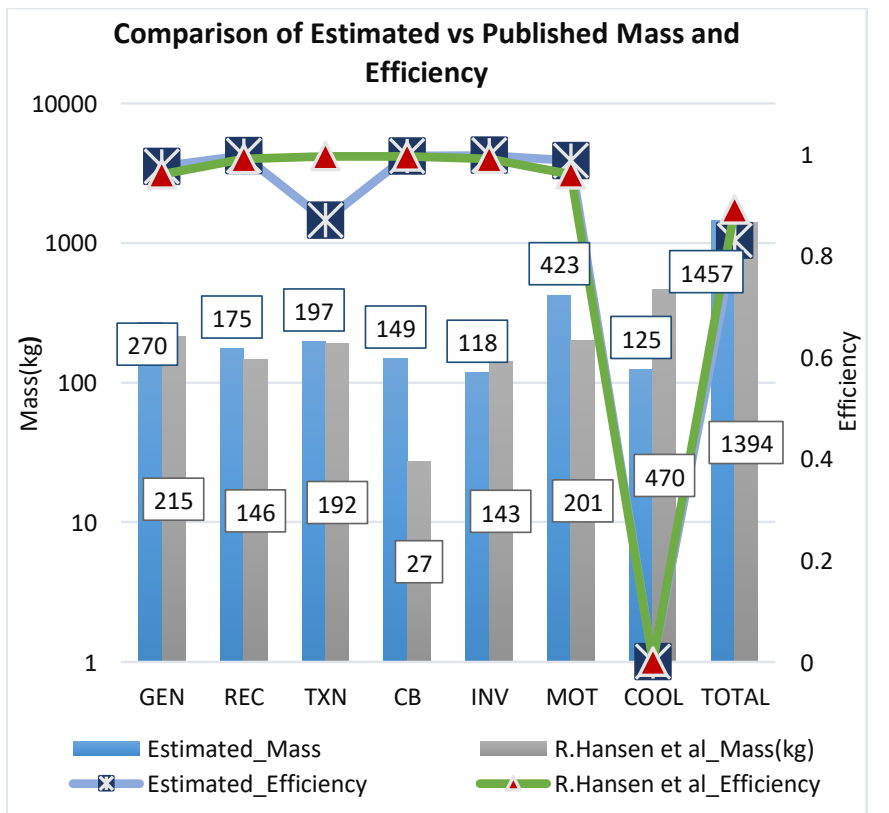

Fig. 19. Components Mass and Efficiency Comparison.

\section{CONCLUSION}

The procedure for selecting the optimal voltage for a turboelectric propulsion system has been presented. This is based on the relationship between fan size and RPM to meet the thrust requirement and the motor voltage to deliver the RPM. The obtained voltage level for the motor is imposed on all devices that constitute the propulsion system. The presented approach shows a close relationship between the fan dimensions, thrust requirement and the system operational voltage. Major determinants of the selected voltage are the stage loading coefficient, speed and torque requirement of the fan. At low speeds and voltages, the propulsion system mass was driven more by the electric machines and cooling system while at high speed and voltages, the power electronics devices had more contribution.

Further investigation would be required to see how different motor topologies impact the derived voltage, size and performance of the propulsion system. The extent of adaptability of the proposed methods to superconducting and battery powered aircrafts has not been investigated. Also, a procedure to determine the range of stage loading coefficient of fans, proposed for electrical propulsion is required. This would consider blade configurations and will further narrow the voltage selection process.

\section{REFERENCES}

[1] H. D. Kim, G. V. Brown, and J. L. Felder, "Distributed Turboelectric Propulsion for Hybrid Wing Body Aircraft," 2008 International Powered Lift Conference, pp. 1-11, 2008.

[2] R. Wahls, R. Del Rosario, and G. Follen, "Overview of the NASA $\mathrm{N}+3$ Advanced Transport Aircraft Concept Studies," in 2nd UTIASMITACS International Workshop on Aviation and Climate Change, 2010, pp. 1-45.

[3] M. Darecki et al., "Flightpath 2050 Europe's vision for aviation: Report of the high level group on aviation research," European Commission, Luxembourg, EUR 098 EN, 2011.

[4] V. Bulc and B. Piccard, "European Aviation Environmental Report," EASA, EEA, EUROCONTROL, Germany, TO-01-15323-EN-N, 2016. doi: 10.2822/385503.

[5] J. Felder, R. Jansen, C. Bowman, A. Jankovsky, and R. Dyson, "Overview of NASA Electrified Aircraft Propulsion (EAP) Research for Large Subsonic Transports," pp. 1-25, 2017, doi: 10.2514/6.2017-4701.

[6] J. L. Felder, H. D. Kim, and G. V. Brown, "Turboelectric Distributed Propulsion Engine Cycle Analysis for Hybrid-WingBody Aircraft," 47th AIAA Aerospace Sciences Meeting including the New Horizons Forum and Aerospace Exposition, no. January, p. AIAA 2009-1132, 2009, doi: 10.2514/6.2009-1132.

[7] J. L. Felder, "NASA N3-X with Turboelectric Distributed Propulsion," in Disruptive Green Propulsion Technologies Conference, 2014, pp. 1-18.

[8] J. L. F. Benjamin T. Schiltgen, "Aeropropulsive Interaction and Thermal System Integration within the ECO-150: A Turboelectric Distributed Propulsion Airliner with Conventional Electric Machines," in AIAA Aviation Technology, Integration, and Operations Conference, 2016, no. June, pp. 1-18, doi: 10.2514/6.2016-4064.

[9] A. Dubois, M. Van Der Geest, J. Bevirt, J. Aviation, S. Cruz, and N. Glenn, "Design of an Electric Propulsion System for SCEPTOR," American Institute of Aeronautics and Astronautics, no. June, pp. 130, 2016.

[10] M. K. Bradley, T. J. Allen, and C. K. Droney, "Subsonic Ultra Green Aircraft Research Phase II - Volume I - Truss Braced Wing Design Exploration," NASA, Hampton, VA, USA., NASA/CR2015-218704, 2015.

[11] C. L. Bowman, T. V. Marien, and J. L. Felder, "Turbo- and HybridElectrified Aircraft Propulsion Concepts for Commercial Transport," pp. 1-8, 2018, doi: 10.2514/6.2018-4984.

[12] I. Angesicht et al., "Konzeptstudie „Propulsive Fuselage “: Geringere Emissionen durch ein Extra-Triebwerk Concept study , Propulsive Fuselage ": Adding an extra engine to reduce emissions," 2014.

[13] P. C. Vratny, "Conceptual Design Methods of Electric Power Architectures for Hybrid Energy Aircraft," PhD Thesis, Technische Universität München, München, Germany, 2018.

[14] I. Christou, A. Nelms, M. Husband, and I. Cotton, "Choice of optimal voltage for more electric aircraft wiring systems," IET Electrical Systems in Transportation, vol. 1, no. 1, pp. 24-30, 2011, doi: 10.1049/iet-est.2010.0021.

[15] G. Paul et al., "Architecture, Voltage and Components for a Turboelectric Distributed Propulsion Electric Grid ( AVC-TeDP)," NASA, Hampton, VA, USA., NASA/CR-2015-218713, 2015.

[16] M. J. Armstrong et al., "Architecture, Voltage and Components for a Turboelectric Distributed Propulsion Electric Grid ( AVC-TeDP )Final Report," NASA, Hampton, VA, USA., NASA/CR-2015218440, 2015.

[17] M. Pagonis, "Electrical Power Aspects Of Distributed Propulsion Systems In Turbo-Electric Powered Aircraft," Ph.D Thesis, Cranfield University, Cranfield, United Kingdom, 2015.

[18] R. Vepa, "Modeling and Dynamics of HTS Motors for Aircraft Electric Propulsion," Aerospace, vol. 5, no. 1, p. 21, 2018, doi: 10.3390/aerospace5010021.

[19] J. W. Chapman and J. S. Litt, "An Approach for Utilizing Power Flow Modeling for Simulations of Hybrid Electric Propulsion Systems," 2018 AIAA/IEEE Electric Aircraft Technologies 
Symposium (EATS), pp. 1-12, 2018, doi: 10.2514/6.2018-5018.

[20] A. C. Saravanamuttoo, H. I. H., Rogers. G. F. C., Cohen, H., Straznicky, P. V., Nix, Gas turbine theory, 7th ed. Harlow: Pearson, 2017.

[21] J. Welstead and J. L. Felder, "Conceptual Design of a Single-Aisle Turboelectric Commercial Transport with Fuselage Boundary Layer Ingestion," pp. 1-34, 2016, doi: 10.2514/6.2016-1027.

[22] Federal Aviation Administration (FAA), Title 14 Part 33.73 Power or Thrust Response. Federal Aviation Regulation (FAR), 2018.

[23] K. Petermaier, "Electric propulsion components with high power densities for aviation," in Transformational Vertical Flight Workshop, 2015, pp. 1-16.

[24] R. J. Christie, A. Dubois, and J. M. Derlaga, "Cooling of Electric Motors Used for Propulsion on SCEPTOR," NASA, Hampton, VA, USA., NASA/TM-2017-219134, 2017.

[25] I. Bouzidi, N. Bianchi, and A. Masmoudi, "An approach to the sizing of electric motors devoted to aerospace propulsion systems," COMPEL - The International Journal for Computation and Mathematics in Electrical and Electronic Engineering, vol. 33, no. 5. pp. 1527-1540, 2014, doi: 10.1108/COMPEL-12-2013-0426.

[26] C. Gerada, M. Galea, and A. Kladas, "Electrical Machines for High Performance Aerospace Applications," Proceedings - 2015 IEEE Workshop on Electrical Machines Design, Control and Diagnosis, WEMDCD 2015, pp. 79-84, 2015, doi:

10.1109/WEMDCD.2015.7194513.

[27] R. Jansen, C. Bowman, and A. Jankovsky, "Sizing Power Components of an Electrically Driven Tail Cone Thruster and a Range Extender," in 16th AIAA Aviation Technology, Integration, and Operations Conference, 2016, no. June, pp. 1-10, doi: 10.2514/6.2016-3766.

[28] A. Hughes and T. J. E. Miller, "Comparative design and performance analysis of air-cored and iron-cored synchronous machines," Proceedings of the Institution of Electrical Engineers, 1977.

[29] J. A. Tapia, A. Parviainen, J. Pyrhonen, P. Lindh, and R. R. Wallace, "Optimal design procedure for an external rotor permanent-magnet machine," Proceedings - 2012 20th International Conference on Electrical Machines, ICEM 2012, pp. 2695-2701, 2012, doi: 10.1109/ICElMach.2012.6350267.

[30] H. Cho, A. Yoon, N. J. Renner, and K. S. Haran, "Detailed Electromagnetic Analysis of a High Specific Power Slotless Permanent Magnet Motor with Imbalanced Armature Windings," 2017, pp. 1-2.

[31] A. Yoon, F. Arastu, D. Lohan, J. Xiao, and K. Haran, "Direct-Drive Electric Motor for STARC-ABL Tail-Cone," no. August, pp. 1-10, 2019.

[32] B. J. Chalmers, Electric Motor Handbook. London: ButterworthHeinemann, 1988.

[33] X. Yi, A. Yoon, and K. S. Haran, "Multi-physics optimization for high-frequency air-core permanent-magnet motor of aircraft application," 2017 IEEE International Electric Machines and Drives Conference, IEMDC 2017, 2017, doi: 10.1109/IEMDC.2017.8002293.

[34] X. Ding, M. Du, T. Zhou, H. Guo, C. Zhang, and F. Chen, "Comprehensive comparison between SiC-MOSFETs and Si-IGBTs based electric vehicle traction systems under low speed and light load," Energy Procedia, vol. 88, pp. 991-997, 2016, doi: 10.1016/j.egypro.2016.06.124.

[35] M. Feurtado et al., "High-Performance $300 \mathrm{~kW} 3$-Phase SiC Inverter Based on Next Generation Modular SiC Power Modules," in PCIM Europe 2019; International Exhibition and Conference for Power Electronics, Intelligent Motion, Renewable Energy and Energy Management, 2019, no. May, pp. 1-8.

[36] D. Graovac, M. Pürschel, and A. Kiep, "MOSFET Power Losses Calculation Using the Data- Sheet Parameters," Infineon, Neubiberg, Germany, Application Note 2006-07-31, 2006. "Thermal design of capacitors for power electronics," 2014 https://www.tdk-

electronics.tdk.com/download/530862/26dc0a865c4f059ca5613940 d3d4dcf2/pdf-thermaldesign.pdf.

[38] Matthew Feurtado, "300kW Three-Phase Inverter Reference Design User Guide," 2019.

https://www.wolfspeed.com/downloads/dl/file/id/1500/product/421/ crd300da12e_xm3_application_note.pdf.

[39] J. Chin, S. L. Schnulo, and A. Smith, "Transient Thermal Analyses of Passive Systems on SCEPTOR X-57," in AIAA Aviation Technology, Integration, and Operations Conference, 2017, pp. 113, doi: 10.2514/6.2017-3784.

[40] S. J. Kim, D. K. Kim, and H. H. Oh, "Comparison of fluid flow and thermal characteristics of plate-fin and pin-fin heat sinks subject to a parallel flow," Heat Transfer Engineering, vol. 29, no. 2, pp. 169_ 177, 2008, doi: 10.1080/01457630701686669.

[41] J. W. Chapman, K. R. Hunker, J. W. Connolly, E. J. Stalcup, and A Chicatelli, "Modeling and Control Design for a Turboelectric Single Aisle Aircraft Propulsion System," pp. 1-19, 2018, doi: 10.2514/6.2018-5010.

[42] “SEMIKRON_DataSheet_SKM350MB120SCH17_21920420," 2018. https://www.semikron.com/dl/servicesupport/downloads/download/semikron-datasheetskm350mb120sch17-21920420/.

[43] "Film Capacitors-Power Electronic Capacitors MKP DC B2562," 2016. https://docs.rs-online.com/e5e7/0900766b81697f31.pdf.

[44] D. Zhang, J. He, and D. Pan, "A Megawatt-Scale Medium-Voltage High-Efficiency High Power Density 'SiC+Si' Hybrid Three-Level ANPC Inverter for Aircraft Hybrid-Electric Propulsion Systems,"

IEEE Transactions on Industry Applications, vol. 55, no. 6, pp. 5971-5980, 2019, doi: 10.1109/TIA.2019.2933513.

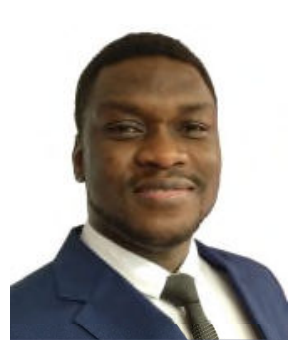

Kingsley Ibrahim received the B.Eng. degree from Madonna University, Rivers State, Nigeria in 2009. He has worked as a telecommunications power and network engineer with Huawei for 5 years, with experience in site power management, equipment installation, operation and maintenance. $\mathrm{He}$ is currently completing a Ph.D. at Cranfield University. U.K, where he has implemented a 400W turboelectric test facility. His research interests include design feasibility, electrical power and thermal management for future aircraft propulsion concepts.

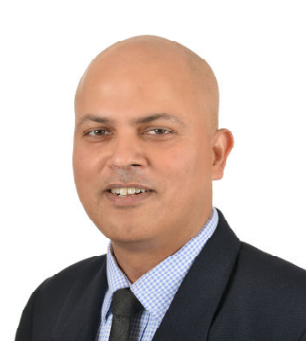

Dr. Suresh Sampath received the M.Sc., degree in Scientific Computation and Simulation and the Ph.D. degree in gas turbines from Cranfield University in 2003. He is the head of gas turbine systems and operations and the director of continuing professional development (CPD) at the propulsion engineering center, school of aerospace, transport \& manufacturing (SATM) Cranfield University, U.K.

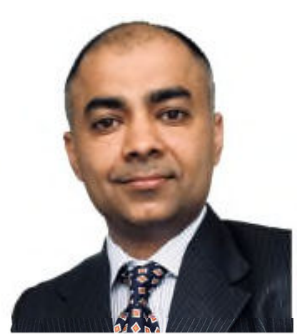

Dr. Devaiah Nalianda received the M.Sc., and Ph.D. degrees in thermal power and aerospace propulsion from Cranfield University in 2009 and 2012 respectively. He is currently a lecturer and the propulsion system performance and integration lead at the propulsion engineering center, school of aerospace, transport and manufacturing, Cranfield University, U.K. He is also the technical lead for a collaborative project between NASA and Cranfield University and has made a substantial contributions in the CLEAN SKY project and other EU framework projects. His research focus is the conceptual development and application of distributed propulsion systems for civil aircraft. 
2020-06-23

\section{Optimal voltage and current selection for turboelectric aircraft propulsion networks}

Ibrahim, Kingsley

IEEE

Ibrahim K, Sampath S, Nalianda D. (2020) Optimal voltage and current selection for turboelectric aircraft propulsion networks. IEEE Transactions on Transportation Electrification, Volume 6, Issue 4, December 2020, pp. 1625-1637 https://doi.org/10.1109/TTE.2020.3004308

Downloaded from Cranfield Library Services E-Repository 